\title{
Editorial
}

\section{Non-Specific Lipid Transfer Proteins: A Protein Family in Search of an Allergenic Pattern}

\author{
Gabriele Gadermaier \\ Christian Doppler Laboratory for Biosimilar Characterization, Department of Molecular Biology, University of \\ Salzburg, Salzburg, Austria
}

The globalized economy has facilitated the introduction of numerous novel foods into our diets. These are often exotic fruits and vegetables that are promoted due to claims of beneficial health properties. Among them, pomegranate (Punica granatum), endemic to the Middle East and India, is now available throughout Europe partly due to promotion of its antioxidant activity. However, pomegranate has recently been shown to trigger immediate hypersensitivity including anaphylactic reactions $[1,2]$. Molecular-based investigations on pomegranate extract show that nonspecific lipid transfer proteins (nsLTPs) are involved in the development of adverse reactions. Due to their compact fold, members of this protein family demonstrate a high resistance to thermal and gastric treatment and they are involved in local but also severe systemic allergic reactions predominantly affecting the Mediterranean population. NsLTPs are present in plant food and vegetables, but also in pollen and latex [3].

In an earlier study, two pomegranate nsLTP isoallergens were purified from the natural source showing divergent immunological properties [1]. A follow-up study by Bolla et al. [4] identified the primary sequence of pomegranate nsLTPs and their immunological behavior as well as analyzing the role of the major peach allergen, Pru p 3, as a main sensitizer. Using degenerated primers based on published nsLTP sequences, the authors identified three different full-length cDNA sequences, which were designated as Pun g 1.0101, Pun g 1.0201 and Pun g 1.0301 by the WHO/IUIS Allergen Nomenclature Sub-

\section{KARGER}

E-Mail karger@karger.com

www.karger.com/iaa committee. Sequence identity between the three mature protein sequences is quite low, ranging from 66 to $68 \%$. These isoforms demonstrated $62-65 \%$ sequence identity to Pru p 3. Interestingly, higher sequence identities were observed with Gossypium spp. (72\%), Sorghum bicolor (67\%) and Zea mays (66\%).

Although the study enrolled only a limited number of pomegranate-allergic patients $(n=6)$, surprisingly, a highly complex pattern of specific IgE recognition to pomegranate and peach nsLTP could be observed [4]. All pomegranate-allergic patients were additionally sensitized to Pru p 3 (CAP class 1-4) but, interestingly, 4 of the 6 tolerated peach ingestion, suggesting strongly that a clinical association of pomegranate and peach allergy is not mandatory. In fact, the observation that Pru p 3 did not inhibit IgE reactivity to Pun $g 1$ isoallergens for all tested patients' sera suggests the existence of Pru p 3-unrelated epitopes. However, in order to unequivocally clarify the relevance of the newly identified Pun $g 1$ isoallergens, purified recombinant molecules should be tested, preferably in a functional assay (e.g. mediator release).

In recent years, numerous IgE-binding nsLTPs have been identified and characterized to varying degrees. However, large-scale population studies including numerous nsLTPs from different sources are still lacking. The question of the primary sensitizer, in particular, has not been fully addressed. NsLTPs were shown to mediate: (1) type I plant food allergy [3], (2) pollen allergy [5], (3) pollen-food syndrome [6] and (4) food allergy leading to 
respiratory symptoms [7]. Clearly, Pru p 3 plays a central role in most of the nsLTP-mediated allergies and was shown to be involved in food-dependent exercise-induced anaphylaxis [8]. However, other plant foods, unrelated to peach and pollen sources (e.g. mugwort and plane tree), have also been reported to play a role in the LTP syndrome [9]. Using a murine model, the mugwort pollen nsLTP (Art v 3) was shown to induce a more pronounced antibody response than Pru p 3. Furthermore, a complete absence of IgE cross-reactivity between Pru p 3 and Art v 3 was observed in mediator release assays [10]. In real life, patients are frequently exposed to different nsLTP-containing sources, making it virtually impossible to discriminate between IgE cross-reactivity and independent cosensitization by direct-detection assays. On a speculative basis, sensitization to nsLTPs from different sources (plant food and pollen) might even enhance the immune response in a synergistic manner and potentially lead to epitope spreading.

Members of the nsLTP family have several properties in common, like their conserved alpha-helical fold and their proteolytic and thermal stability. However, in contrast to their conserved fold, their primary sequences can be highly divergent with similarities that range from 20 to $99 \%$. Apart from botanically closely related members, antibody cross-reactivity between nsLTPs is, in general, very difficult to predict. This seems to also be true for nsLTP isoallergens from the very same source, as shown in the study by Bolla et al. [4] as well as in a previous report on different green bean nsLTP isoallergens [11]. The bottom line is that recognition of nsLTPs seems to be highly patient-specific and might involve diverse epitopes with the potential to cross-react or not. All these findings pose a crucial question: Is it sufficient to use Pru p 3 as the only marker molecule for nsLTPtriggered allergies?

In summary, the study by Bolla et al. [4] on the different isoallergens of pomegranate Pun $g 1$ highlighted the heterogeneity of nsLTPs and their immune recognition. Larger panels of recombinant molecules for direct and quantitative cross-inhibition analysis might be the key for putting together the puzzle of nsLTP-triggered allergy. In addition, determination of IgE-binding epitopes, both linear and nonsequential, could help to find common allergenicity patterns within this protein family and their role in the development of clinical symptoms.

\section{Acknowledgements}

The financial support by the Austrian Federal Ministry of Economy, Family and Youth and the National Foundation of Research, Technology and Development is gratefully acknowledged.

\section{References}

1 Zoccatelli G, Dalla Pellegrina C, Consolini M, Fusi M, Sforza S, Aquino G, Dossena A, Chignola R, Peruffo A, Olivieri M, Rizzi C: Isolation and identification of two lipid transfer proteins in pomegranate (Punica granatum). J Agric Food Chem 2007;55: 11057-11062.

2 Almeida EM, Bartolome B, Faria EG, Sousa NG, Luis AS: Pomegranate anaphylaxis due to cross-reactivity with Peach LTP (Pru p 3). Allergol Immunopathol (Madrid) 2013, Epub ahead of print.

-3 Egger M, Hauser M, Mari A, Ferreira F, Gadermaier G: The role of lipid transfer proteins in allergic diseases. Curr Allergy Asthma Rep 2010;10:326-335.

4 Bolla M, Zenoni S, Scheurer S, Vieths S, San Miguel Moncin MM, Olivieri M, Antico A, Ferrer M, Berroa F, Enrique E, Avesani L, Marsano F, Zoccatelli G: Pomegranate $(P u-$ nica granatum L.) expresses several nsLTP isoforms characterized by different IgE-binding properties. Int Arch Allergy Immunol 2014;164:112-121.
5 Tordesillas L, Sirvent S, Diaz-Perales A, Villalba M, Cuesta-Herranz J, Rodriguez R, Salcedo G: Plant lipid transfer protein allergens: no cross-reactivity between those from foods and olive and Parietaria pollen. Int Arch Allergy Immunol 2011;156:291-296.

-6 Gao ZS, Yang ZW, Wu SD, Wang HY, Liu ML, Mao WL, Wang J, Gadermaier G, Ferreira F, Zheng M, van Ree R: Peach allergy in China: a dominant role for mugwort pollen lipid transfer protein as a primary sensitizer. J Allergy Clin Immunol 2013;131:224-226.e221-223.

7 Sanchez-Lopez J, Tordesillas L, Pascal M, Munoz-Cano R, Garrido M, Rueda M, Vilella R, Valero A, Diaz-Perales A, Picado C, Bartra J: Role of Art $\mathrm{v} 3$ in pollinosis of patients allergic to Pru p 3. J Allergy Clin Immunol 2014;133: 1018-1025.e1013.

-8 Romano A, Scala E, Rumi G, Gaeta F, Caruso C, Alonzi C, Maggioletti M, Ferrara R, Palazzo P, Palmieri V, Zeppilli P, Mari A: Lipid transfer proteins: the most frequent sensitizer in Italian subjects with food-dependent exercise-induced anaphylaxis. Clin Exp Allergy 2012;42:1643-1653.
Pascal M, Munoz-Cano R, Reina Z, Palacin A, Vilella R, Picado C, Juan M, Sanchez-Lopez J, Rueda M, Salcedo G, Valero A, Yague J, Bartra J: Lipid transfer protein syndrome: clinical pattern, cofactor effect and profile of molecular sensitization to plant-foods and pollens. Clin Exp Allergy 2012;42:15291539.

10 Gadermaier G, Hauser M, Egger M, Ferrara R, Briza P, Santos KS, Zennaro D, Girbl T, Zuidmeer-Jongejan L, Mari A, Ferreira F: Sensitization prevalence, antibody cross-reactivity and immunogenic peptide profile of Api g 2, the non-specific lipid transfer protein 1 of celery. PLoS One 2011;6:e24150.

11 Zoccatelli G, Pokoj S, Foetisch K, Bartra J, Valero A, Del Mar San Miguel-Moncin M, Vieths S, Scheurer S: Identification and characterization of the major allergen of green bean (Phaseolus vulgaris) as a non-specific lipid transfer protein (Pha v 3). Mol Immunol 2010;47:1561-1568. 